\title{
Long-Term Depression of NMDA Receptor-Mediated Synaptic Transmission Is Dependent on Activation of Metabotropic Glutamate Receptors and Is Altered to Long- Term Potentiation by Low Intracellular Calcium Buffering
}

\author{
Sarah C. Harney, ${ }^{1}$ Michael Rowan, ${ }^{2}$ and Roger Anwyl ${ }^{1}$ \\ Departments of ${ }^{1}$ Physiology and ${ }^{2}$ Pharmacology and Therapeutics, Trinity College, Dublin 2, Ireland
}

\begin{abstract}
Synaptic plasticity of NMDA receptor (NMDAR)-mediated transmission was investigated in the rat dentate gyrus in vitro. Isolated NMDAR EPSCs were recorded from granule cells of the dentate gyrus in response to stimulation of the medial perforant path. Long-term potentiation (LTP) or long-term depression (LTD) of NMDAR EPSCs was observed in response to brief high-frequency stimulation (HFS), with the direction and extent of plasticity dependent on the concentration and type (EGTA vs BAPTA) of the intracellular $\mathrm{Ca}^{2+}$ buffer. $^{2}$ LTD was induced in higher concentrations of EGTA and BAPTA than LTP, and BAPTA was $\sim 100$-fold more potent than EGTA. Although LTD was induced in a high concentration of EGTA $(10 \mathrm{~mm})$, a high concentration of BAPTA $(10 \mathrm{~mm})$ blocked both LTP and LTD. LTP of AMPA receptor (AMPAR)-EPSCs exhibited a lower dependency on $\mathrm{Ca}^{2+}$ buffering than LTP of NMDAR EPSCs, because LTP of AMPAR EPSCs was induced by HFS in high EGTA $(10 \mathrm{~mm})$. We also identified a role for metabotropic glutamate receptor 5 (mGluR5) in NMDAR plasticity. HFS LTD was blocked by the group I/II mGluR antagonist LY341495 ((2S)-2-amino-2-[(1S,2S)-2-carboxycycloprop-1-yl]3(xanth-9-yl)propanoic acid) and by the mGluR5-selective antagonist 2-methyl-6-(phenylethynyl)pyridine hydrochloride (MPEP). Similarly, low-frequency stimulation-induced LTD of NMDAR EPSCs was also blocked by MPEP. These findings suggest that the direction of plasticity of NMDARs is determined by the intracellular free $\mathrm{Ca}^{2+}$ concentration and is dependent on activation of mGluR5.
\end{abstract}

Key words: NMDA; LTD; metabotropic glutamate receptor; dentate gyrus; patch clamp; calcium

\section{Introduction}

NMDA receptors (NMDARs) have a pivotal role in the regulation of synaptic transmission in the CNS. In particular, the long channel open time and high $\mathrm{Ca}^{2+}$ permeability of the NMDAR result in a prolonged synaptic conductance coupled with a large $\mathrm{Ca}^{2+}$ influx. Activation of the NMDAR triggers extensive signal transduction cascades that regulate plasticity of synaptic transmission as well as the formation and elimination of synapses (ConstantinPaton, 1990; Malenka and Nicoll, 1999; Carroll and Zukin, 2002). Although plasticity of AMPA receptor (AMPAR) synaptic transmission has been studied extensively (Malenka and Bear, 2004), much less is known about plasticity of the NMDAR-mediated transmission. Certain studies have shown that long-term potentiation (LTP) of NMDAR EPSCs is induced by high-frequency stimulation (HFS) in CA1 (Bashir et al., 1991; Berretta et al., 1991; Xie et al., 1992; Aniksztejn and Ben-Ari, 1995; Clark and Collingridge, 1995; Yi et al., 1995; Grosshans et al., 2002) and the dentate gyrus (O'Connor et al., 1994, 1995), but other studies have found little or no LTP of NMDAR EPSCs (Kauer et al., 1988;

\footnotetext{
Received July 4, 2005; revised Dec. 9, 2005; accepted Dec. 9, 2005.

This work was supported by Science Foundation Ireland.

Correspondence should be addressed to Dr. Roger Anwyl, Department of Physiology, Trinity College, Dublin 2, Ireland. E-mail: ranwyl@tcd.ie.

DOI:10.1523/JNEUROSCI.2753-05.2006

Copyright $\odot 2006$ Society for Neuroscience $\quad$ 0270-6474/06/261128-05\$15.00/0
}

Muller et al., 1988; Perkel et al., 1993; Liao et al., 1995; Selig et al., 1995; Heynen et al., 2000). Induction of NMDAR long-term depression (LTD) after low-frequency stimulation (LFS) has also been observed in CA1 (Selig et al., 1995; Yi et al., 1995; Morishita et al., 2005). Little is known about the mechanisms underlying plasticity of NMDAR EPSCs. A role for activation of metabotropic glutamate receptors (mGluRs) and protein kinase C (PKC) stimulation was established in the induction of LTP of NMDAR EPSCs in the dentate gyrus (O'Connor et al., 1994, 1995). LTD of NMDAR EPSCs was either dependent on (Yi et al., 1995) or independent (Morishita et al., 2005) of activation of mGluRs and was not associated with a change in coefficient of variation (Selig et al., 1995).

In the present study, we describe the induction of LTP and LTD of NMDAR EPSCs in the dentate gyrus and show that the direction of plasticity of NMDAR EPSCs is altered by the level of buffering of intracellular $\mathrm{Ca}^{2+}$ and is dependent on the activation of mGluRs.

\section{Materials and Methods}

Transverse hippocampal slices $(400 \mu \mathrm{m})$ were prepared from the brains of male Sprague Dawley rats (3-4 weeks old; 40-80 g). Rats were decapitated, and the brains were removed quickly and placed in ice-cold artificial CSF (ACSF) containing the following (in $\mathrm{mm}$ ): $125 \mathrm{NaCl}, 25$ $\mathrm{NaHCO}_{3}, 2.5 \mathrm{KCl}, 1.25 \mathrm{NaH}_{2} \mathrm{PO}_{4}, 2 \mathrm{CaCl}_{2}, 1 \mathrm{MgCl}_{2}$, and 25 D-glucose, bubbled with $95 \% \mathrm{O}_{2}$ and $5 \% \mathrm{CO}_{2}$. Slices were cut using a vibratome 
A HFS LTD, 10 mM EGTA
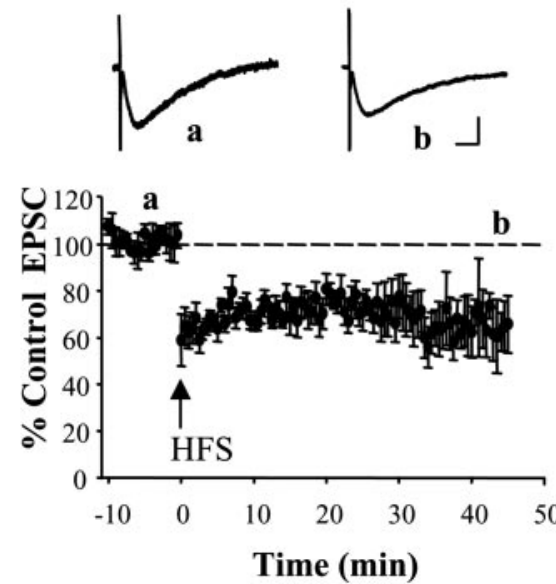

D HFS LTD, 0.2 mM BAPTA
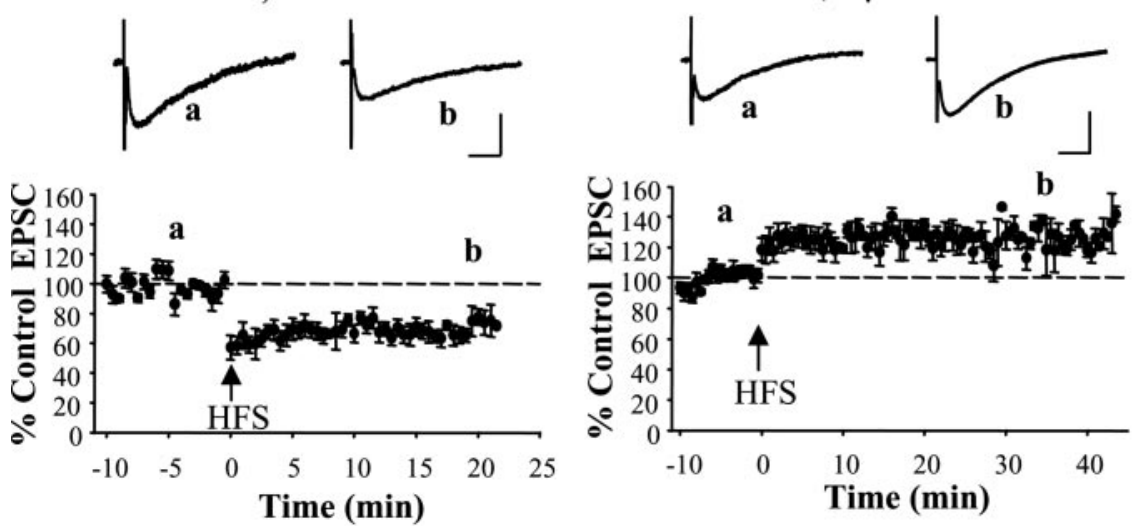

E HFS LTP, $2 \mu$ M BAPTA
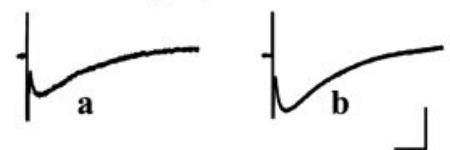

C AMPAR HFS LTP, 10 mM EGTA

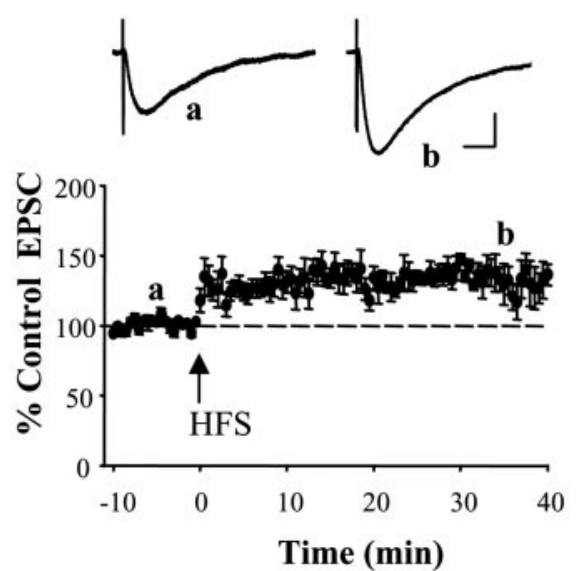

F HFS, 10 mM BAPTA
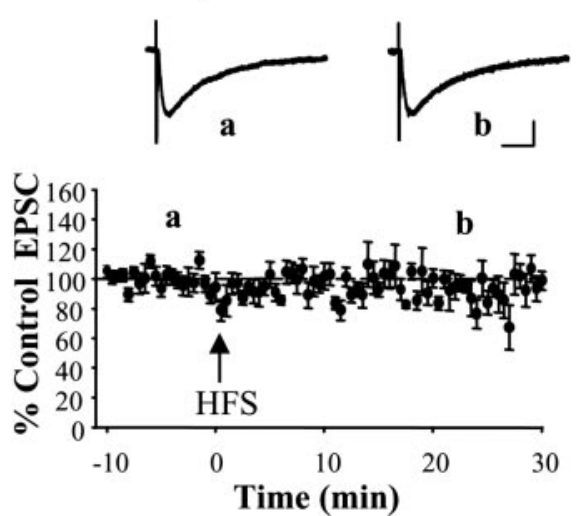

Figure 1. Induction of LTP or LTD of NMDAR EPSCS by HFS is dependent on intracellular calcium buffering. $A$, LTD of NMDAR EPSC $s$ is induced by HFS under conditions of high intracellular $C a^{2+}$ buffering ( $10 \mathrm{~mm}$ EGTA intracellular solution; $n=6$ ). Traces show averaged EPSCs before and after HFS at the time points ( $\mathrm{a}$ and $\mathrm{b}$ ) indicated on the graph. Calibration: $10 \mathrm{pA}, 20 \mathrm{~ms}$. $\boldsymbol{B}$, HFS induces LTP of NMDAR EPSCs under conditions in which intracellular $\mathrm{Ca}^{2+}$ buffering is reduced to $0.2 \mathrm{~mm}$ EGTA ( $\left.n=5\right)$. Calibration: $50 \mathrm{pA}, 20 \mathrm{~ms}$. C, LTP of AMPAR EPSCs is induced by HFS with $10 \mathrm{~mm}$ EGTA in the pipette solution $(n=5)$. Calibration: $30 \mathrm{pA}, 30 \mathrm{~ms}$. $\boldsymbol{D}$, LTD was induced by HFS with $0.2 \mathrm{~mm}$ BAPTA in the intracellular solution $(n=5)$. Calibration: $10 \mathrm{pA}, 20 \mathrm{~ms}$. $E$, LTP was induced by HFS with low intracellular BAPTA $(0.002 \mathrm{~mm} ; n=7)$. Calibration: 20 pA, 20 ms. F, BAPTA (10 mm) blocked induction of either LTD or LTP $(n=7)$. Calibration: 20 pA, 20 ms. Error bars indicate SE.

(Intracell, Herts, UK) and placed in an incubation chamber, in standard $1 \mathrm{~mm} \mathrm{MgCl}$-containing ACSF, for at least $1 \mathrm{~h}$ before recordings.

Whole-cell patch-clamp recordings were made from granule cells of the dentate gyrus, visualized using an upright microscope (BX51 WI; Olympus, Middlesex, UK) with infrared differential interference contrast optics. Patch pipettes were pulled from thick-walled borosilicate glass (World Precision Instruments, Sarasota, FL) and had a resistance of 3-5 $\mathrm{M} \Omega$ when filled with intracellular solution containing the following (in $\mathrm{mm}$ ): $140 \mathrm{~K}$-gluconate, $10 \mathrm{HEPES}, 20$ phosphocreatine, $2 \mathrm{Mg}_{2} \mathrm{ATP}, 0.3$ NaGTP, pH 7.3 and 290-300 mOsm. In addition, the intracellular solutions used contained one of the following calcium buffers (in mM): 0.2 or 10 EGTA; $0.002,0.02,0.2$ or 10 BAPTA. Slices were maintained at $30-$ $33^{\circ} \mathrm{C}$ during recordings. Granule cells were voltage clamped at $-70 \mathrm{mV}$, and EPSCs were evoked by stimulation with a bipolar tungsten wire electrode placed in the middle one-third of the dentate gyrus molecular layer to activate the medial perforant pathway. Control EPSCs were evoked at a test frequency of $0.033 \mathrm{~Hz}$, using the lowest stimulus strength that reliably produced currents $(10-30 \mu \mathrm{A} ; 100 \mu$ s pulses). HFS consisted of eight trains, each of eight stimuli at $200 \mathrm{~Hz}$, intertrain interval of $2 \mathrm{~s}$, repeated three times. LFS consisted of stimulation at $1 \mathrm{~Hz}$ for $15 \mathrm{~min}$. Both HFS and LFS were applied under current-clamp conditions. NMDAR EPSCs were recorded in picrotoxin (100 $\mu \mathrm{M})$, 6-cyano-7quinoxaline-2,3-dione (CNQX) $(10 \mu \mathrm{M})$, and glycine $(20 \mu \mathrm{M})$. HFS or LFS induction stimuli were delivered to cells after recording of a stable baseline for $10 \mathrm{~min}$, and this was always within $15 \mathrm{~min}$ of attaining breakthrough in the whole-cell recording configuration. The amplitude of LTP/LTD was expressed 35-40 min after stimulation. Recordings were made using an Axoclamp 1D amplifier (Molecular Devices, Union City, CA). Signals were filtered at $5 \mathrm{kHz}$ using a 4-pole Bessel filter and were digitized at $10 \mathrm{kHz}$ using a Digidata $1320 \mathrm{~A}$ analog-digital interface (Molecular Devices). Data were acquired and analyzed using pClamp 9.0 and Axoclamp software (Molecular Devices).

All salts used were obtained from Sigma (St. Louis, MO). Picrotoxin, CNQX, and DL-2-aminophosphonopentanoic acid (DL-AP5) were from Sigma, and (2S)-2-amino-2-[(1S,2S)-2-carboxycycloprop-1-yl]-3(xanth-9yl)propanoic acid (LY341495) and 2-methyl-6-(phenylethynyl)pyridine hydrochloride (MPEP) were from Tocris Cookson (Avonmouth, UK). Data are means \pm SEM; statistical significance was evaluated using paired $t$ tests $(p<0.05)$.

\section{Results}

Calcium-dependent plasticity of NMDAR EPSCs

We recorded pharmacologically isolated NMDAR EPSCs in granule cells of dentate gyrus at $-70 \mathrm{mV}$, which is close to the resting potential, and in the presence of $1 \mathrm{mM} \mathrm{Mg}^{2+}$, to maintain physiological conditions in which NMDARs are subject to block by $\mathrm{Mg}^{2+}$ ions. In these conditions, NMDAR EPSCs had a mean amplitude of $34 \pm 2 \mathrm{pA}$ and a $10-90 \%$ rise time of $4.7 \pm 0.3 \mathrm{~ms}$, and decayed with a time constant of $40 \pm 2 \mathrm{~ms}(n=37)$. The 


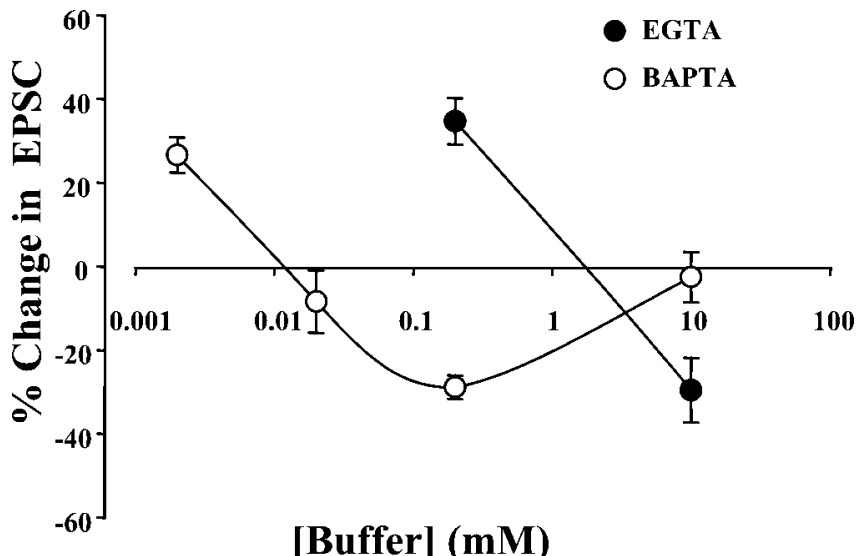

Figure 2. Bidirectional plasticity of NMDAR EPSCs as a function of intracellular calcium buffering. Similar LTP was induced with $0.2 \mathrm{~mm}$ EGTA and $0.002 \mathrm{~mm}$ BAPTA, whereas LTD was induced with $10 \mathrm{~mm}$ EGTA and $0.2 \mathrm{~mm}$ BAPTA. A high concentration of BAPTA $(10 \mathrm{~mm})$ prevented either LTP or LTD. Error bars indicate SE.

recorded EPSCs displayed a characteristic current-voltage relationship with strong outward rectification (supplemental Fig. 1, available at www.jneurosci.org as supplemental material) and were abolished by perfusion of AP5 (EPSC amplitude, $4 \pm 2 \mathrm{pA}$ after $10 \mathrm{~min}$ in $50 \mu \mathrm{M}$ AP5; $n=5$ ) (supplemental Fig. 2, available at www.jneurosci.org as supplemental material), confirming that they were evoked purely by activation of NMDARs.

In initial experiments, plasticity was induced by a brief HFS, and the effect of two intracellular $\mathrm{Ca}^{2+}$ buffers, EGTA and BAPTA, was investigated on the extent and direction of plasticity. EGTA and BAPTA have a similar high affinity for $\mathrm{Ca}^{2+}\left(K_{\mathrm{d}}\right.$, $\sim 160 \mathrm{nM}$ ) but differ in their $\mathrm{Ca}^{2+}$ binding kinetics. EGTA is a relatively slow buffer with an on-rate for $\mathrm{Ca}^{2+}$ binding of $10^{6}$ $\mathrm{M}^{-1} \cdot \mathrm{s}^{-1}$ compared with $10^{8} \mathrm{M}^{-1} \cdot \mathrm{s}^{-1}$ for BAPTA, $\sim 100$-fold different. No significant differences in the amplitude or kinetics of the test EPSCs were recorded in the different concentrations of buffers. For example, in 10 mm EGTA (amplitude, $34 \pm 2$ pA; decay time constant, $40 \pm 2 \mathrm{~ms} ; n=37$ ) or $10 \mathrm{~mm}$ BAPTA (amplitude, $27 \pm 3 \mathrm{pA}$; decay time constant, $37 \pm 5 \mathrm{~ms} ; n=7$; $p>0.05)$. Figure 1 illustrates the effect of different intracellular concentrations of EGTA and BAPTA on the induction of LTP and LTD. LTD $(71 \pm 8 \% ; n=6 ; p<0.01)$ was induced by HFS in $10 \mathrm{~mm}$ EGTA (Fig. $1 A$ ) and $0.2 \mathrm{~mm}$ BAPTA $(71 \pm 3 \% ; n=5 ; p<$ 0.01 ) (Fig. 1D). Weak LTD was observed in two cells with 0.02 mM BAPTA $(92 \pm 7 \%$ ) (data not shown but included in Fig. 2). LTP was induced in 0.2 mM EGTA $(135 \pm 6 \% ; n=5 ; p<0.01)$ (Fig. $1 B$ ) and 0.002 mm BAPTA $(127 \pm 4 \% ; n=7 ; p<0.01)$ (Fig. $1 E)$. Both LTP and LTD occurred rapidly, with a rise to a maximum level induced immediately after HFS. A high concentration of BAPTA $(10 \mathrm{mM})$ inhibited both LTP and LTD $(n=99 \pm 6 \%$; $n=7 ; p>0.05)($ Fig. $1 F)$.

These findings are summarized in Figure 2, which illustrates the relationship between NMDAR plasticity and intracellular exogenous calcium buffer concentration. Low concentrations of either buffer allowed induction of LTP after HFS, whereas at higher concentrations, LTD was induced by the same stimulus. The curve for BAPTA lay 100-fold to the left of that for EGTA. From this graph, we estimated the half-effective buffer concentration $\left(\mathrm{EC}_{50}\right.$, the buffer concentration that we estimate would permit half-maximal LTP or LTD) for EGTA and BAPTA. For LTD, the $\mathrm{EC}_{50}$ values were $3 \mathrm{~mm}$ and $>10 \mathrm{~mm}$ for BAPTA and EGTA, respectively, and $5 \mu \mathrm{M}$ and $0.7 \mathrm{~mm}$ for BAPTA and EGTA for LTP, respectively.
The plasticity of NMDAR EPSCs and AMPAR EPSCs was briefly compared. For AMPAR plasticity, recordings were performed in the absence of CNQX in the extracellular medium and with $10 \mathrm{mM}$ EGTA in the pipette solution. HFS induced LTP of AMPAR EPSCs (138 $\pm 7 \%$ of control; $n=5 ; p<0.01)$ (Fig. $1 C$ ). AMPAR LTP had a similar magnitude and rapid induction as NMDAR LTP. These findings confirmed that we could induce AMPAR LTP with whole-cell recordings, under the same conditions used for NMDAR plasticity experiments.

\section{HFS-induced plasticity of NMDAR EPSCs requires activation of mGluR5}

We investigated whether activation of mGluRs had a role in LTD of NMDAR EPSCs, because mGluR-dependent LTD of AMPARs induced by LFS has been described in CA1 (Oliet et al., 1997) and dentate gyrus (Camodeca et al., 1999). In the presence of the mGluR antagonist LY341495 $(100 \mu \mathrm{M})$, at a concentration that blocks all mGluRs, and using an intracellular solution containing $10 \mathrm{~mm}$ EGTA, HFS induced only a short-term depression, and the EPSC amplitude returned to baseline values within 5 min of the stimulus ( $98 \pm 5 \%$ of control at $20-25 \min$ post-HFS; $n=6$; $p>0.05$ ) (Fig. 3A). To determine the mGluR subgroup required for HFS LTD, we tested the effect of the mGluR5-selective antagonist MPEP ( $1 \mu \mathrm{M}$; higher concentrations of MPEP were not used because of a frequency-dependent block of NMDAR EPSCs after HFS). MPEP $(1 \mu \mathrm{M})$ blocked HFS-induced LTD (EPSC amplitude, $101 \pm$ $6 \%$ of control; $n=5 ; p>0.05$ ) (Fig. $3 B$ ). This demonstrates that activation of mGluR5 is necessary for HFS LTD.

\section{mGluR5 is also required for LFS LTD of NMDAR EPSCs}

LTD induction is more commonly associated with stimulation at low frequencies. In experiments using standard $10 \mathrm{~mm}$ EGTA intracellular solution, LFS induced LTD of NMDAR EPSCs similar to that induced by HFS ( $75 \pm 5 \%$ of control; $n=5 ; p<0.05$ ) (Fig. $3 C$ ). LFS LTD was also blocked by MPEP ( $1 \mu \mathrm{M})$ (Fig. $3 D$ ). Three of four cells tested displayed short-term depression in response to LFS in the presence of MPEP, and in the remaining cell, EPSCs were slightly potentiated after LFS. The averaged EPSC amplitude measured $104 \pm 11 \%$ of control at $30-35 \mathrm{~min}$ postLFS $(n=4 ; p>0.05)$ (Fig. $3 D)$. These findings show that mGluR5 activation either during LFS or HFS in conditions of strong postsynaptic calcium buffering results in depression of NMDAR-mediated synaptic transmission.

\section{Discussion}

Here, we have shown that the same stimulus, brief HFS, induced LTP or LTD of NMDAR EPSCs, with the extent and direction of the plasticity dependent on the level and nature of the intracellular $\mathrm{Ca}^{2+}$ buffer. Intracellular $\mathrm{Ca}^{2+}$ buffering was manipulated using different concentrations of EGTA and BAPTA. LTD was induced with strong exogenous intracellular $\mathrm{Ca}^{2+}$ buffering, and conversely, LTP was induced when intracellular $\mathrm{Ca}^{2+}$ buffering was relatively weak. As illustrated in Figure 2, in which the magnitude of plasticity is plotted as a function of buffer concentration, the curve for BAPTA was displaced $\sim 100$-fold to the left of EGTA, showing that EGTA was much less effective than BAPTA at buffering the $\mathrm{Ca}^{2+}$ responsible for inducing plasticity. EGTA and BAPTA have a similar, high affinity for $\mathrm{Ca}^{2+}\left(K_{\mathrm{d}}, \sim 160 \mathrm{nM}\right)$ but differ in their binding kinetics. EGTA is a relatively slow buffer with an on-rate for $\mathrm{Ca}^{2+}$ binding of $10^{6} \mathrm{M}^{-1} \cdot \mathrm{s}^{-1}$ compared with $10^{8}$ $\mathrm{M}^{-1} \cdot \mathrm{s}^{-1}$ for BAPTA, $\sim 100$-fold different. Thus, interestingly, the difference in efficacy between BAPTA and EGTA in modulating plasticity closely matched their differences in $\mathrm{Ca}^{2+}$ binding kinetics. 
A HFS, 10 mM EGTA

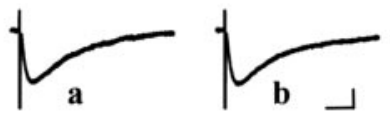

$100 \mu \mathrm{M}$ LY341495

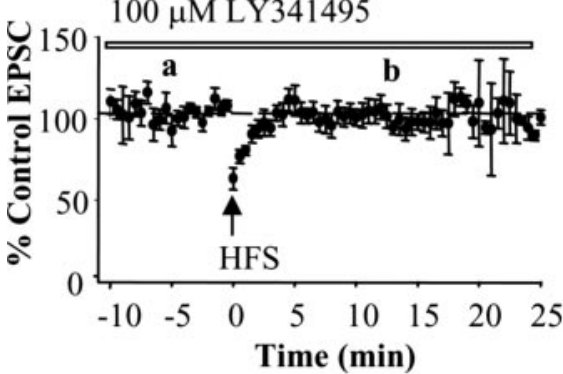

C LFS, 10 mM EGTA

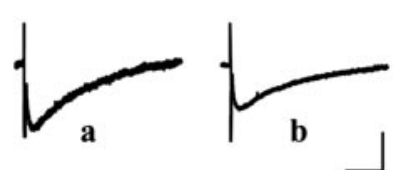

D LFS, 10 mM EGTA
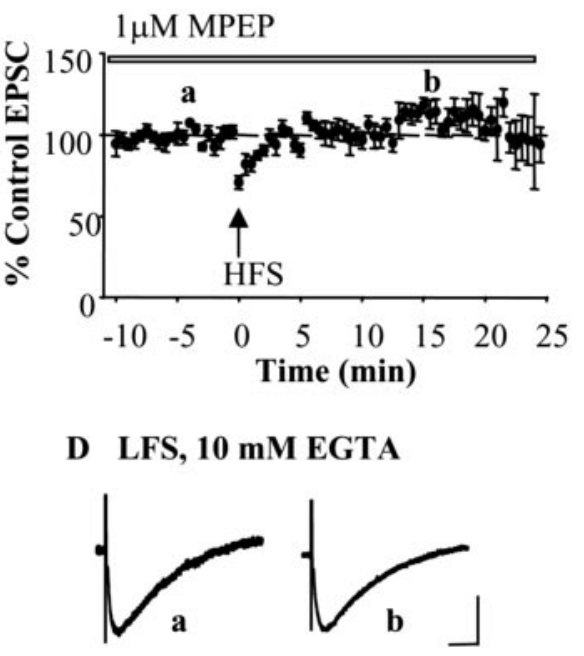

$1 \mu \mathrm{M}$ MPEP
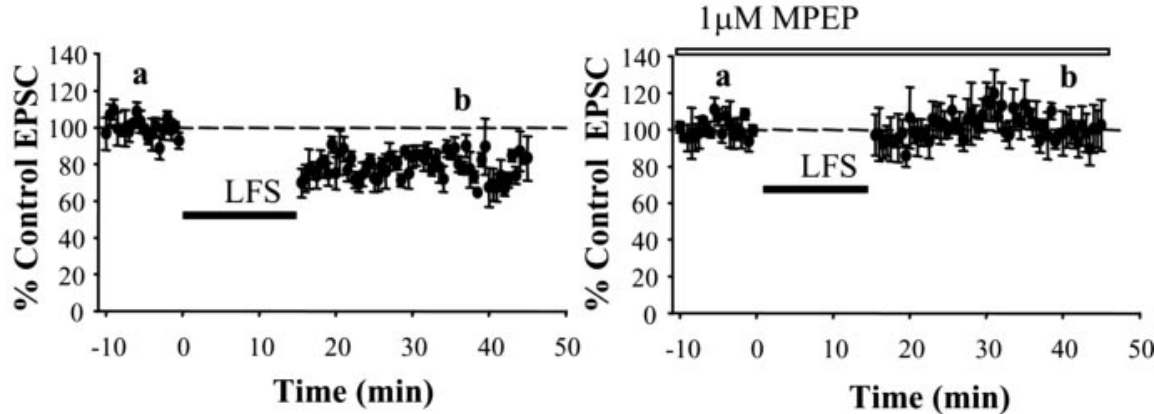

Figure 3. HFS- and LFS-induced LTD is mGluR5 receptor dependent. $\boldsymbol{A}$, HFS LTD of NMDAR EPSCs (recorded with $10 \mathrm{~mm}$ EGTA intracellular solution) is inhibited by the group I/II mGluR antagonist LY341495 (100 $\mu \mathrm{m} ; n=6)$. Traces show averaged EPSCS before and after HFS, at the time points (a and b) indicated on the graph. Calibration: $10 \mathrm{pA}, 20 \mathrm{~ms}$. $\boldsymbol{B}$, The mGluR5-specific antagonist MPEP $(1 \mu \mathrm{m})$ blocks HFS LTD $(n=5)$. Calibration: $20 \mathrm{pA}, 20 \mathrm{~ms}$. C, Control LFS LTD of NMDAR EPSCs $(n=5)$. Calibration: $20 \mathrm{pA}, 20 \mathrm{~ms}$. D, LFS LTD was blocked by the mGluR5-specific antagonist MPEP $(1 \mu \mathrm{m} ; n=4)$. Calibration: $20 \mathrm{pA}, 20$ ms. Error bars indicate $S E$.

EGTA and BAPTA have been used in previous studies to distinguish $\mathrm{Ca}^{2+}$ signals with different temporal and spatial characteristics, with particular emphasis on transmitter release. Because BAPTA and EGTA have a similar affinity for $\mathrm{Ca}^{2+}$, they will buffer steady-state $\mathrm{Ca}^{2+}$ to the same extent at relatively long distances from the site of $\mathrm{Ca}^{2+}$ influx. However, EGTA is effective only at modulating a relatively slow or diffuse calcium signal, whereas the faster binding kinetics of BAPTA allow it to modulate a fast signal and to buffer $\mathrm{Ca}^{2+}$ very close to the site of influx. At the squid giant synapse, it was concluded that the $\mathrm{Ca}^{2+}$ influx channel and the target site were very close, within a few $\mathrm{nm}$, because EGTA did not suppress transmitter release even at very high concentrations (up $80 \mathrm{~mm}$ ), whereas BAPTA suppressed release with an $\mathrm{EC}_{50}$ of $\sim 0.5 \mathrm{~mm}$ (Adler et al., 1991; Neher, 1998). Such $\mathrm{EC}_{50}$ values are in the same range as those for BAPTA and EGTA on LTD of NMDAR EPSCs in the present studies $\left(\mathrm{EC}_{50}\right.$ values for BAPTA and EGTA for the suppression of NMDAR LTD were $\sim 3$ and $>10 \mathrm{~mm}$, respectively). Thus, our findings clearly indicate that there are spatiotemporal differences in the $\mathrm{Ca}^{2+}$ signals required for the induction of NMDAR LTP and LTD.

The role of intracellular $\mathrm{Ca}^{2+}$ in determining the direction of plasticity of NMDAR EPSCs described here is in agreement with the "calcium hypothesis" of LTP and LTD. This hypothesis states that the direction of plasticity is controlled by the magnitude of the rise in intracellular $\mathrm{Ca}^{2+}$, with a large elevation in $\mathrm{Ca}^{2+}$ (evoked by strong depolarization and strong $\mathrm{Ca}^{2+}$ influx) inducing LTP, and smaller $\mathrm{Ca}^{2+}$ elevations (evoked by weak depolarization and weak $\mathrm{Ca}^{2+}$ influx) inducing LTD (Lisman, 1989; Artola and Singer, 1993). The hypothesis was formulated for AMPAR plasticity and has been supported by studies showing that, first, stimuli that normally induced LTP elicited LTD if $\mathrm{Ca}^{2+}$ influx was partially suppressed (Cummings et al., 1996); second, the amplitude and duration of elevating $\mathrm{Ca}^{2+}$ from a caged compound determined the induction of either LTP or LTD (Yang et al., 1999); and third, direct measurements of intracellular $\mathrm{Ca}^{2+}$ showed that LTP induction is associated with a higher $\mathrm{Ca}^{2+}$ rise than LTD (Cormier et al., 2001). The present studies are the first to provide evidence that the calcium hypothesis also applies to NMDAR plasticity.

Recent studies have suggested a role for different NMDAR subtypes in the induction of AMPAR LTP and LTD, with NR2A subunit-containing receptors required for LTP and NR2B receptor subtypes required for LTD (Liu et al., 2004; Massey et al., 2004) (but see also Berberich et al., 2005). The NMDAR EPSCs described here were mediated by both NR2A- and NR2Bcontaining receptors, because EPSC amplitude was reduced by $25 \%$ in ifenprodil (10 $\mu \mathrm{M} ; n=5)$. Also, in the presence of ifenprodil $(10 \mu \mathrm{M})$, LTD of NMDAR EPSCs $(n=2)$ was induced by HFS and this was similar to control recordings (S. C.

Harney, unpublished observations).

We compared the effect of HFS on NMDAR EPSCs with LTP of AMPAR EPSCs. Using an intracellular solution containing 10 mM EGTA, HFS induced LTD of NMDAR EPSCs, but LTP of AMPAR EPSCs. In comparison, the same amplitude of LTP of NMDAR EPSCs was induced in 0.2 mM EGTA. Thus, EGTA was much more effective at inhibiting LTP of NMDAR EPSCs than of AMPAR EPSCs, demonstrating a closer distance between the $\mathrm{Ca}^{2+}$ influx channel and the target site for NMDAR EPSCs than for AMPAR EPSCs. Previous studies investigating the effect of the PKC-calcium-activated kinase $\beta(\mathrm{CAK} \beta)$-Src cascade on LTP of AMPARs and NMDARs have shown that the $\mathrm{Ca}^{2+}$ signal responsible for activation of the PKC-CAK $\beta$-Src cascade is also more spatially restricted to the vicinity of NMDARs than AMPARs (Kotecha et al., 2003).

We have shown that HFS- and LFS-induced LTD were dependent on activation of mGluRs, and specifically mGluR5, because the LTD was prevented by the nonselective mGluR antagonist LY341495 and the mGluR5 antagonist MPEP. This is the first study to demonstrate a group I mGluR-dependent LTD of NMDARs, although the group I mGluR agonist DHPG $[(R S)$ 3,5-dihydroxyphenylglycine] has been shown previously to in- 
duce LTD of NMDAR in CA1 (Snyder et al., 2001), and a group I mGluR-dependent LTD of AMPARs has been shown previously in many areas of the brain (Anwyl, 2006), including CA1 (Oliet et al., 1997; Palmer et al., 1997; Fitzjohn et al., 1999) and dentate gyrus (Camodeca et al., 1999). In the present study, we induced LTD of NMDAR EPSCs using two protocols (HFS with high $\mathrm{Ca}^{2+}$ buffering or LFS), and our results suggest that both forms of LTD share a common pathway requiring mGluR5. The group I mGluR dependency of LTD of NMDAR EPSCs in the present study is in contrast to the study by Morishita et al. (2005), who demonstrated an mGluR-independent LTD of NMDAR LTD in CA1. The difference may be a regional one between the dentate gyrus and CA1, or alternatively, may be attributable to different solutions in the recording pipette in the two studies. Most notably, the recording pipette used in the study of Morishita et al. (2005) contained QX-314 (lidocaine $N$-ethyl bromide), an agent known to block a variety of ion channels.

Bidirectional synaptic plasticity of AMPAR-mediated transmission at excitatory synapses in hippocampus has been described in detail and is an important feature of computational models of hippocampal function. In this study, we demonstrated bidirectional modification of NMDAR EPSCs, and we identified the level of intracellular $\mathrm{Ca}^{2+}$ as a critical modulator of such NMDAR plasticity. It remains to be tested whether, in agreement with theoretical models of AMPAR plasticity (Shouval et al., 2002), activity-dependent changes in NMDAR $\mathrm{Ca}^{2+}$ influx via NMDARs or changes in NMDAR properties influence the outcome of plasticity at perforant path-granule cell synapses.

\section{References}

Adler EM, Augustine GJ, Duffy SN, Charlton MP (1991) Alien intracellular calcium chelators attenuate neurotransmitter release at the squid giant synapse. J Neurosci 11:1496-1507.

Aniksztejn L, Ben-Ari Y (1995) Expression of LTP by AMPA and/or NMDA receptors is determined by the extent of NMDA receptors activation during the tetanus. J Neurophysiol 74:2349-2357.

Anwyl R (2006) Induction and expression mechanisms of postsynaptic NMDA receptor-independent homosynaptic long-term depression. Prog Neurobiol, in press.

Artola A, Singer W (1993) Long-term depression of excitatory synaptic transmission and its relationship to long-term potentiation. Trends Neurosci 16:480-487.

Bashir ZI, Alford S, Davies SN, Randall AD, Collingridge GL (1991) Longterm potentiation of NMDA receptor-mediated synaptic transmission in the hippocampus. Nature 49:156-158.

Berberich S, Punnakkal P, Jensen V, Pawlak V, Seeburg PH, Hvalby O, Kohr G (2005) Lack of NMDA receptor subtype selectivity for hippocampal long-term potentiation. J Neurosci 25:6907-6910.

Berretta N, Berton F, Brunelli M, Capogna M, Francesconi W (1991) Longterm potentiation of NMDA receptor-mediated EPSP in guinea pig hippocampal slices. Eur J Neurosci 3:850-854.

Camodeca N, Breakwell NA, Rowan MJ, Anwyl R (1999) Induction of LTD by activation of group I mGluR in the dentate gyrus in vitro. Neuropharmacology 38:1597-1606.

Carroll RC, Zukin RS (2002) NMDA-receptor trafficking and targeting: implications for synaptic transmission and plasticity. Trends Neurosci 25:571-577.

Clark KA, Collingridge GL (1995) Synaptic potentiation of dualcomponent excitatory postsynaptic currents in the rat hippocampus. J Physiol (Lond) 482:39-52.

Constantin-Paton M (1990) NMDA receptor as a mediator of activitydependent synaptogenesis in the developing brain. Cold Spring Harb Symp Quant Biol 55:431-443.

Cormier RJ, Greenwood AC, Connor JA (2001) Bidirectional synaptic plasticity correlated with the magnitude of dendritic calcium transients above a threshold. J Neurophysiol 85:399-406.

Cummings JA, Mulkey RM, Nicoll RA, Malenka RC (1996) $\mathrm{Ca}^{2+}$ signaling requirements for long-term depression in the hippocampus. Neuron 16:825-833.

Fitzjohn SM, Kingston AE, Lodge D, Collingridge GL (1999) DHPG- induced LTD in area CA1 of juvenile rat hippocampus: characterization and sensitivity to novel mGluR antagonists. Neuropharmacology 38:1577-1583.

Grosshans DR, Clayton DA, Coultrap SJ, Browning MD (2002) LTP leads to rapid surface expression of NMDA but not AMPA receptors in adult rat CA1. Nat Neurosci 5:27-33.

Heynen AJ, Quinlan EM, Bae DC, Bear MF (2000) Bidirectional, activitydependent regulation of glutamate receptors in the adult hippocampus in vivo. Neuron 28:527-536.

Kauer JA, Malenka RC, Nicoll RA (1988) A persistent polysynaptic modification mediates long-term potentiation in the hippocampus. Neuron 471:481-500.

Kotecha SA, Jackson MF, Al-Mahrouki A, Roder JC, Orser B, McDonald JF (2003) Co-stimulation of mGluR5 and NMDAR is required for potentiation of excitiatory synaptic transmission to hippocampal neurons. J Biol Chem 278:27742-27749.

Liao D, Hessler NA, Malinow R (1995) Activation of postsynaptically silent synapses during pairing-induced LTP in CA1 region of hippocampal slice. Nature 375:400-404.

Lisman J (1989) A mechanism for the Hebb and the anti-Hebb processes underlying learning and memory. Proc Natl Acad Sci USA 86:9574-9578.

Liu L, Wong TP, Pozza MF, Lingenhoehl K, Wang Y, Sheng M, Auberson YP, Wang YT (2004) Role of NMDA receptor subtypes in governing the direction of plasticity. Science 304:1021-1024.

Malenka RC, Bear MF (2004) LTP and LTD: an embarrassment of riches. Neuron 44:5-21.

Malenka RC, Nicoll RA (1999) Long-term potentiation-a decade of progress. Science 285:1870-1874.

Massey PV, Johnson BE, Moult PR, Auberson YP, Brown MW, Molnar E, Collingridge GL, Bashir ZI (2004) Differential roles of NR2A and NR2B-containing NMDA receptors in cortical long-term potentiation and long-term depression. J Neurosci 24:7821-7828.

Morishita W, Marie H, Malenka RC (2005) Distinct triggering and expression mechanisms underlie LTD of AMPAR and NMDAR synaptic responses. Nat Neurosci 8:1043-1050.

Muller D, Joly M, Lynch G (1988) Contributions of quisqualate and NMDA receptors to the induction and expression of LTP. Science 242:1694-1697.

Neher E (1998) Usefulness and limitations of linear approximations to the understanding of $\mathrm{Ca}^{++}$signals. Cell Calcium 24:345-357.

O'Connor JJ, Rowan MJ, Anwyl R (1994) Long-lasting enhancement of NMDA receptor-mediated synaptic transmission by metabotropic glutamate receptor activation. Nature 367:557-559.

O'Connor JJ, Rowan MJ, Anwyl R (1995) Tetanically induced LTP involves a similar increase in the AMPA and NMDA receptor components of the excitatory postsynaptic current: investigations of the involvement of mGlu receptors. J Neurosci 15:2013-2020.

Oliet SHR, Malenka RC, Nicoll RA (1997) Two distinct forms of long-term depression co-exist in CA1 hippocampal pyramidal cells. Neuron 18:969-982.

Palmer MJ, Irving AJ, Seabrook GR, Jane DE, Collingridge GL (1997) The group I mGluR agonist DHPG induces a novel form of LTD in the CA1 region of the hippocampus. Neuropharmacology 36:1517-1532.

Perkel DJ, Petrozzino JJ, Nicoll RA, Connor JA (1993) The role of $\mathrm{Ca}^{2+}$ entry via synaptically activated NMDA receptors in the induction of longterm potentiation. Neuron 11:817-823.

Selig DK, Lee HK, Bear MF, Malenka RC (1995) Reexamination of the effects of MCPG on hippocampal LTP, LTD, and depotentiation. J Neurophysiol 74:1075-1082.

Shouval HZ, Bear MF, Cooper LN (2002) A unified model of NMDA receptor-dependent bidirectional synaptic plasticity. Proc Natl Acad Sci USA 99:10831-10836.

Snyder EM, Philpot BD, Huber KM, Dong X, Fallon JR, Bear MF (2001) Internalization of ionotropic glutamate receptors in response to mGluR activation. Nat Neurosci 4:1079-1085.

Xie X, Berger TW, Barrionuevo G (1992) Isolated NMDA receptor-mediated synaptic responses express both LTP and LTD. J Neurophysiol 67:1009-1013.

Yang SN, Tang YG, Zucker RS (1999) Selective induction of LTP and LTD by postsynaptic $\left[\mathrm{Ca}^{2+}\right]_{\mathrm{i}}$ elevation. J Neurophysiol 81:781-787.

Yi PL, Chang FC, Tsai JJ, Hung CR, Gean PW (1995) The involvement of metabotropic glutamate receptors in long-term depression of $N$-methylD-aspartate receptor-mediated synaptic potential in the rat hippocampus. Neurosci Lett 185:207-210. 